Rev. Elet. em Gestão, Educação e Tecnologia Ambiental (e-ISSN: 2236-1170)

\title{
ARBORIZAÇÃO DE VIAS PÚBLICAS DO BAIRRO CAMOBI, SANTA MARIA, RS.
}

\author{
Denise Andréia Szymczak ${ }^{1}$, Flávia Gizele Konig Brun², Eleandro José Brun ${ }^{3}$, Márcio Carlos Navroski ${ }^{4}$, \\ Eduardo Kneipp Londero ${ }^{5}$ \\ ${ }^{1}$ Engenheira Florestal, mestranda do Programa de Pós-Graduação em Engenharia Florestal da Universidade Federal de \\ Santa Maria, departamento de Ciências Florestais, Santa Maria, Rio Grande do Sul. deniseszymczak@gmail.com. \\ ${ }^{2}$ Engenheira Florestal, Mestre. Professora da Universidade Tecnológica Federal do Paraná - campus Dois Vizinhos, \\ departamento de Ciências Florestais, Dois Vizinhos, Paraná flaviagizele@gmail.com \\ ${ }^{3}$ Engenheiro Florestal, Professor Doutor da Universidade Tecnológica Federal do Paraná - Campus Dois Vizinhos, de \\ Ciências Florestais, Dois Vizinhos, Paraná eleandrobrun.utfpr@gmail.com, ${ }^{4}$ Engenheiro Florestal, Doutorando do \\ Programa de Pós Graduação em Engenharia Florestal da Universidade Federal de Santa Maria, departamento de \\ Ciências Florestais, Santa Maria, Rio Grande do Sul, marcionavroski@gmail.com, \\ ${ }^{5}$ Engenheiro Florestal, Mestre. Supervisor de Supressão vegetal na empresa Engemab - Engenharia e meio \\ ambiente.eklondero@gmail.com
}

http://dx.doi.org/10.5902/223611706207

\section{RESUMO}

Neste estudo foram inventariadas as árvores das vias públicas de cinco Vilas do bairro Camobi, Santa Maria - RS. As espécies mais frequentes tiveram seus padrões morfométricos avaliados e mensurados. Foram contabilizadas 1348 árvores, distribuídas em 61 espécies, 28 nativas e 33 exóticas. A maior frequência de indivíduos foi observada para as espécies de: Lagerstroemia indica L., Caesalpinia peltophoroides, Melia azedarach L., Inga marginata Willd., Ligustro lucidum W. T. Aiton, Handroanthus chrysotrichus (Mart. ex DC) Mattos e Eugenia uniflora L., correspondendo a $61 \%$ do total de árvores. Devido ao aumento de áreas construídas na cidade, ocorreu redução no número de indivíduos, o que também refletiu na idade da arborização do bairro.

Palavras - chave: censo florestal, bioma Mata Atlântica, qualidade de vida, cidades.

\section{ARBORIZATION PUBLIC ROADS OF CAMOBI DISTRICT, SANTA MARIA, RS}

\begin{abstract}
This study inventoried the trees on public roads five villages of Camobi neighborhood, Santa Maria - RS. The most frequent species had their morphometric patterns evaluated and measured. It's 1348 trees were recorded, distributed in 61 species, 28 native and 33 exotic. The higher frequency of individuals was observed for the species: Lagerstroemia indica L., Caesalpinia peltophoroides, Melia azedarach L., Inga marginata Willd., Ligustro lucidum W. T. Aiton, Handroanthus chrysotrichus (Mart. ex DC) Mattos e Eugenia uniflora L., corresponding to $61 \%$ of all trees. Due to the increase in built-up areas in the city, there was a reduction in the number of individuals, which is also reflected in the age of the trees in the Camobi.
\end{abstract}

Keywords: forest census, Atlantic Forest Biome, quality of life, cities. 
Rev. Elet. em Gestão, Educação e Tecnologia Ambiental (e-ISSN: 2236-1170)

\section{INTRODUÇÃO}

As árvores exercem função ecológica, conservando a flora nativa da região, melhorando o ambiente urbano e a estética, embelezando assim as vias públicas (Guzzo, 1993). Proporcionam benefícios a regularidade de clima, redução da velocidade dos ventos, melhoria do ciclo hidrológico do solo, opções de recreação, valorização de imóveis, diminuição dos níveis de ruídos e aumento da diversidade, funcionando como um refúgio à fauna remanescente das cidades (Langowski e Klechowicz, 2001).

De acordo com Gonçalves e Paiva (2004), o ambiente urbano é muito variável e a escolha do vegetal que será plantado dependerá do espaço tridimensional disponível a ele. As árvores têm funções ecológicas importantes para melhor a qualidade de vida das pessoas, como: estruturação de espaços, controle de poluição, controle do ciclo hidrológico, controle de temperaturas, auxílio na ventilação, entre outros.

No Brasil, a arborização de ruas é uma prática recente, que começou a fazer parte do planejamento urbano somente no final do século XIX. As árvores são vegetais muito presentes no ciclo histórico do homem, inicialmente utilizadas como fonte de energia, passando a ser componente das casas, e atualmente está inserida no nosso cotidiano de várias formas (Santos e Teixeira, 2001). Paine et al. (1993) dizem que a arborização urbana representa um ambiente único, sendo quase sempre artificial, que contém uma mistura de espécies endêmicas e exóticas e o máximo de contato com o público.

Para a manutenção da arborização viária das cidades são necessárias algumas ações como: investimento em legislação que defina critérios de manejo para a arborização; apoio ao estudo científico para levantamento do patrimônio arbóreo da cidade; elaboração de planos de arborização e manejo de áreas verdes e; utilização de equipamentos urbanos que se ajustem às necessidades do homem e da cidade. Para tanto, o inventário da arborização tem como objetivo geral conhecer o patrimônio arbustivo e arbóreo de uma localidade (Rocha et al., 2004).

O presente estudo teve como objetivo inventariar as espécies arbóreas utilizadas na arborização de cinco vilas do bairro Camobi, Santa Maria -RS e analisar as condições em que as espécies mais frequentes se encontram em relação aos padrões morfométricos.

\section{MATERIAIS E MÉTODOS}

\section{Caracterização da área de estudo}

O estudo foi realizado no Bairro Camobi, município de Santa Maria, RS. Este bairro teve o início de sua ocupação a partir da Vila Estação Colônia, que se formou de um antigo povoado de imigrantes italianos que recebia o nome de Estação Colônia. Conforme Fontoura (1993), a ocupação inicial se deu no entorno da Estação Ferroviária do Distrito de Estação Colônia, que com a instalação da Universidade Federal e Base Aérea de Santa Maria, e com a instalação de indústrias ao longo da RS-509 (Avenida Prefeito Evandro Behr) iniciou-se o processo de evolução urbana e de articulação entre a Cidade de Santa Maria e a área do Bairro.

A distribuição da população dentro da área, porém se deu de forma desigual, determinada conforme a valorização do espaço, onde as áreas mais valorizadas destinam-se as classes sociais altas, denominadas de "Parques" e receberam melhor infra-estrutura e as áreas menos valorizadas denominadas de "Vilas", constituindo-se de zonas com menor infra-estrutura 
REGETFSM SZYMCZAK et al., v(8), no 8, p. 1611-1625, SET-DEZ, 2012.

Rev. Elet. em Gestão, Educação e Tecnologia Ambiental (e-ISSN: 2236-1170)

Estes locais são: Vila Santos Dumont, Vila Santa Tereza, Vila Assunção, Vila Estação Colônia e Vila Santa Helena, caracterizando-se por serem áreas ocupadas por famílias de baixa renda, sem condições de enfrentar o alto custo econômico de um terreno mais valorizado ou de um aluguel mais elevado nas áreas mais nobres do Bairro (Viera, 1997).

Atualmente, pelo elevado grau de urbanização e densidade demográfica do Bairro Camobi, que conta com uma população de 13.311 habitantes, que correspondem a 5,8\% do total da população urbana do município, as áreas vagas dentro dos Parques residenciais são praticamente inexistentes, o que leva às classes sociais mais altas ocuparem espaços dentro das Vilas, gerando conflitos de paisagem e segregações sociais dentro destes locais.

Devido à extensão deste bairro, e pela grande carência destes locais em infra-estrutura e arborização urbana, tomou-se como área de estudo cinco vilas, respectivamente: Vila Santos Dumont, Vila Santa Tereza, Vila Assunção, Vila Estação Colônia, Vila Santa Helena, que por sua vez equivalem a $216.710 \mathrm{~m}^{2}$ e uma população média de 8.409 habitantes. As áreas de cada vila e avenidas e respectivas localizações encontram-se na Tabela 1.

Tabela 1 - Relação de vilas estudadas com respectivas áreas e coordenadas geográficas. Table 1 - Relationship with their villages studied areas and geographic coordinates.

\begin{tabular}{cccc}
\hline \multirow{2}{*}{ Local de estudo } & \multirow{2}{*}{ Área $\left(\mathrm{m}^{2}\right)$} & \multicolumn{2}{c}{ Coordenadas Geográficas } \\
\cline { 3 - 4 } & & $\mathbf{S}$ & $\mathbf{W}$ \\
\hline Vila Santos Dumont & 66.580 & $29^{\circ} 42^{\prime} 18^{\prime \prime}$ & $53^{\circ} 43^{\prime} 23^{\prime \prime}$ \\
Vila Santa Tereza & 64.620 & $29^{\circ} 42^{\prime} 18^{\prime \prime}$ & $53^{\circ} 43^{\prime} 04^{\prime \prime}$ \\
Vila Assunção & 42.640 & $29^{\circ} 42^{\prime} 18^{\prime \prime}$ & $53^{\circ} 43^{\prime} 50^{\prime \prime}$ \\
Vila Estação Colônia & 19.760 & $29^{\circ} 42^{\prime} 19^{\prime \prime}$ & $53^{\circ} 43^{\prime} 44^{\prime \prime}$ \\
Vila Santa Helena & 23.110 & $29^{\circ} 42^{\prime} 17^{\prime \prime}$ & $53^{\circ} 42^{\prime} 24^{\prime \prime}$ \\
\hline Total & 216.710 & & \\
\hline
\end{tabular}

O clima da região é do tipo subtropical temperado, do tipo "Cfa 2", segundo a classificação de Köppen (Moreno, 1961), caracterizada por temperatura média anual entre 17,9 e $19,2^{\circ} \mathrm{C}$ sendo que a temperatura média do mês mais quente é superior a $22^{\circ} \mathrm{C}$. As chuvas são bem distribuídas ao longo do ano sendo que a precipitação média anual fica em torno de 1400 a 1760 $\mathrm{mm}$.

O relevo apresenta-se suavemente ondulado, caracterizado pela presença de coxilhas e planícies aluviais, com cotas altimétricas variando de 40 a 200 metros, caracterizando uma paisagem sem grande variação altimétrica (Spiazzi, 2002). O solo é classificado como pertencente às Unidades de Mapeamento São Pedro e Santa Maria, sendo que os mesmos denominam-se, respectivamente, como: Argissolo Vermelho distrófico arênico e Argissolo Bruno-Acinzentado alítico úmbrico (Streck, et al., 2008).

Na Figura 1, pode-se visualizar a localização do bairro Camobi, no município de Santa Maria com a demarcação da área onde foi realizado o estudo. 
Rev. Elet. em Gestão, Educação e Tecnologia Ambiental (e-ISSN: 2236-1170)

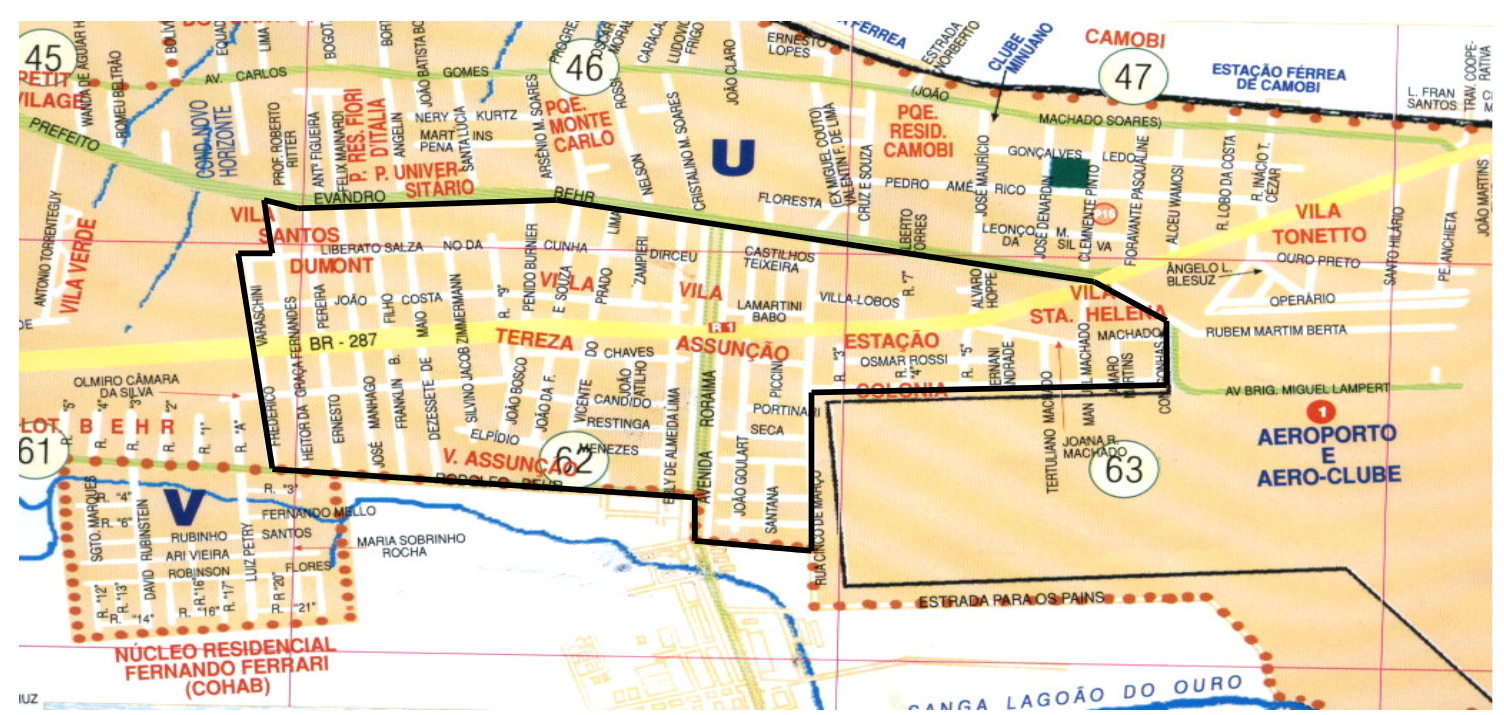

Fontes: Santa Maria Dados (2002), Prefeitura Municipal de Santa Maria (2002).

Figura 1 - Delimitação da área amostral.

Figure 1 - Delimitation of the sampling area.

\section{Metodologia especifica}

Foi realizado um inventário do tipo censo, onde todas as árvores presentes nas calçadas ou próximas a ela tiveram mensurados parâmetros morfométricos e neste trabalho foram apresentados os dados apenas das espécies mais frequentes na arborização. O mesmo foi realizado entre os meses de agosto de 2007 e abril de 2008. Os dados foram coletados em planilha específica, e após foram transferidos para o software Microsoft Office Excel ${ }^{\circledR} 2003$. As espécies mais frequentes foram identificadas in loco, e as demais através de bibliografia adequada Lorenzi (2003), bem como a determinação da origem (nativas ou exóticas). A classificação das famílias botânicas segue as orientações do Angiosperm Phylogeny Group (APG III).

Os Padrões Morfométricos avaliados foram: altura total $(\mathrm{Ht})$, altura de inserção do primeiro galho $(\mathrm{Hg})$, altura de copa $(\mathrm{Hc})$, altura da primeira bifurcação $(\mathrm{Hb})$ e o Diâmetro a altura do Peito (DAP). As alturas foram tomadas com aparelho vertex e, para as árvores onde não foi possível a medição com este aparelho, utilizou-se uma trena de 10 metros. O DAP foi mensurado com suta dendrométrica de precisão e, também dependendo da dificuldade do local, foi medida a Circunferência a altura do Peito (CAP) com fita métrica e posteriormente transformada em DAP pela fórmula: $\mathrm{CAP} / \pi=\mathrm{DAP}$.

\section{RESULTADOS E DISCUSSÃO}

Nas vilas analisadas foram contabilizadas 1348 árvores. Em ordem decrescente, a distribuição foi caracterizada como segue: Santa Tereza, Santos Dumont, Assunção, Santa Helena e Estação Colônia com, 461, 404, 250, 122 e 111 árvores respectivamente (Tabela 2). Estas diferenças em relação ao número de exemplares nas vilas reflete principalmente a identidade da população que a habita e também histórico de ocupação. Brun (2009) relata em seu estudo sobre 
Rev. Elet. em Gestão, Educação e Tecnologia Ambiental (e-ISSN: 2236-1170)

percepção da população destas vilas em relação à arborização que, a Vila Santos Dumont apesar de possuir o maior número de indivíduos possuía muitos problemas em relação a vandalismo o que desestimulava a população a plantar novas árvores.

Ainda segundo essa autora, a vila Assunção, ao contrário da vila anterior, apresenta uma ótima infraestrutura, serviços básicos disponíveis e as vias bem arborizadas. A população é composta, em sua maioria, por funcionários e professores da Universidade Federal de Santa Maria e funcionários da Base Aérea de Santa Maria, e preza mais por um ambiente que proporcione maior qualidade de vida. Na Vila Estação colônia existem segregações sociais na distribuição de espaços dentro de sua área, onde se observaram ruas carentes de infraestrutura básica e com arborização deficitária nas áreas menos valorizadas contrastando com áreas próximas a Rodovia RS 287, onde o padrão econômico é maior.

Há uma diversidade de 61 espécies arbóreas, onde as mais representativas foram: extremosa com 247 indivíduos (18,3\%); sibipiruna com 149 indivíduos (11\%); cinamomo com 134 indivíduos (9,9\%), ligustro com 96 indivíduos (7,1\%); ingá-feijão com 83 (6,2\%); ipê-amarelo com 61 indivíduos (4,5\%); e pitangueira com 54 indivíduos (4\%). Estas sete espécies juntas correspondem a $61 \%$ das árvores das vilas sendo que as outras 54 espécies correspondem a 39,0 \%. O número de espécies encontradas é similar a outros estudos já realizados, como: Santos/SP 65 espécies (Meneghetti, 2003), Nova Iguaçu/RJ - 59 espécies (Rocha et al., 2004), Santo Cristo/RS - 63 espécies (Gerhardt, 2011). Este fato reflete que a diversidade em termos de espécies pose der considerada mediana, entretanto a frequência de indivíduos geralmente é elevada para um conjunto pequeno de espécies.

Em estudo realizado por Teixeira (1999) no Bairro Tancredo Neves em Santa Maria-RS, também foi possível constatar relativa uniformidade das espécies que compõe a arborização: apenas 14 espécies compreendiam 70,6\% da arborização total do bairro. As espécies dominantes foram: cinamomo representando $18,07 \%$, ligustro com $11,62 \%$ e extremosa com $8,32 \%$. Em outros trabalhos de arborização as 10 espécies mais frequentes, corresponderam a 48,33\% em águas de São Pedro-SP (Bortoleto et al. 2007), 71,25\% em Jaboticabal-SP, Silva Filho, (2002) e 48,3\% em Brasília-DF, Rodrigues et al., (1994), mostrando que na cidade de Assis a distribuição de espécies também é irregular em comparação com outros trabalhos, devendo-se adequar melhor esta proporção.

De acordo com Grey e Deneke (1986) apud Teixeira (1999) recomenda-se que a frequência de uma única espécie não ultrapasse a $15 \%$. Por razões estéticas e fitossanitárias, devese estabelecer o número de espécies a utilizar e a proporcionalidade de uso de cada espécie, em relação ao total de árvores a serem plantadas. Considerando o valor citado pelos autores a extremosa pode vir a apresentar problemas de longevidade por meio de ataque de doenças (principalmente oídio). Como a mesma é dominante na arborização das vilas isso representaria um problema estético nas vias públicas. $\quad$ Em estudo realizado por Prass (2004) na cidade de Quinze de Novembro-RS pode-se observar que a espécie de maior ocorrência foi extremosa, com 302 exemplares totalizando $18,9 \%$ dos indivíduos amostrados na cidade. Este valor é assemelha-se muito ao do presente estudo, indicando que tal espécie é largamente utilizada na arborização urbana brasileira. Segundo Brun (2006) devem-se tomar certos cuidados com ligustro (Ligustrum lucidum), espécie comumente utilizada na arborização de vias públicas, pois apresenta propriedades alergênicas que causam Polinose, doença que é preferencial à latitudes maiores que 25 ㅇ. S.

Numa perspectiva muito ampla e generalizada da arborização de cidades brasileiras, observa-se relativa uniformidade quanto ao emprego de certas espécies, vem daí a pouca 
REGETHFSM SZYMCZAK et al., v(8), no 8, p. 1611-1625, SET-DEZ, 2012.

Rev. Elet. em Gestão, Educação e Tecnologia Ambiental (e-ISSN: 2236-1170)

diversidade, concentrando-se a maioria em um número reduzido de espécies, gerando com isso, problemas fitossanitários semelhantes (Souza, 1994). A dominância de uma espécie varia de acordo com a cidade e região do Brasil. Outros trabalhos mostram uma dominância de Caesalpinia peltophoroides na arborização de São Pedro-SP (Bortoleto et al., 2007), Platanus acerifolia em Campos do Jordão-SP (Andrade, 2002), Lagerstroemia indica em Curitiba-PR (Milano, 1984), Tipuana tipu em Jacareí-SP (Faria et al., 2007).

Outra informação relevante do inventário é que 20 espécies apresentam menos de quatro indivíduos distribuídos em toda a área do estudo, reforçando a característica de que na arborização das grandes cidades as maiores frequências de indivíduos estão concentradas em poucas espécies. Em relação ao inventário da arborização do Bairro Camobi realizado por Longhi et al. (2005), nas vilas estudadas verificou-se um descréscimo de $44,0 \%$ nos indivíduos de cinamomo; $39,0 \%$ de ipê-amarelo; $28,6 \%$ de ligustro; $25,2 \%$ de extremosas; $20,6 \%$ em pitangueiras; $12,9 \%$ de sibipiruna e acréscimo de $11 \%$ de ingá-feijão. Essas reduções no número de indivíduos implantados nas vias públicas devem-se principalmente em função do aumento das áreas construídas no Bairro. O aumento de indivíduos de ingá-feijão nas vias públicas está relacionado ao crescimento rápido e ao fornecimento de sombra para as casas. O Brasil possui $80 \%$ de sua população vivendo nas grandes cidades (IBGE, 2000). Em muitas dessas cidades, a elevada concentração populacional com consequente construção de moradias contribuem para a redução da cobertura vegetal.

Dentre as espécies identificadas no inventário, 28 (46\%) correspondem a nativas e 33 (54\%) a exóticas. Apesar do município de Santa Maria pertencer ao ecossistema da Floresta Estacional subtropical, bioma Mata Atlântica, há predominância de espécies exóticas na composição da arborização. Neste caso, extremosa, cinamomo e ligustro caracterizam essa predominância. A primeira pela beleza de sua flor e a facilidade das podas, as demais pela rusticidade e fácil adaptação ao solo pobre em nutrientes. Dados semelhantes foram obtidos em outras localidades do país onde as espécies exóticas corresponderam à maioria da população, como: 


\section{REGEIAUFSM}

Rev. Elet. em Gestão, Educação e Tecnologia Ambiental (e-ISSN: 2236-1170)

Tabela 2 - Inventário da arborização viária de cinco vilas do Bairro Camobi, Santa Maria - RS, 2008.

Table 2 - Arborization Inventory in five village Camobi district, Santa Maria - RS, 2008.

\begin{tabular}{|c|c|c|c|c|c|c|c|c|c|c|c|c|c|c|}
\hline \multirow{2}{*}{ Nome Comum } & \multirow{2}{*}{ Nome Científico } & \multirow{2}{*}{0} & \multicolumn{2}{|c|}{ Santa Helena } & \multicolumn{2}{|c|}{ Assunção } & \multicolumn{2}{|c|}{ Estação Colônia } & \multicolumn{2}{|c|}{ Santa Tereza } & \multicolumn{2}{|c|}{ Santos Dumont } & \multicolumn{2}{|c|}{ Total } \\
\hline & & & N.I & $\%$ & N.I & $\%$ & N.I & $\%$ & N.I & $\%$ & N.I & $\%$ & N.I & $\%$ \\
\hline Extremosa & Lagerstroemia indica L. & E & 23 & 18,9 & 32 & 12,8 & 11 & 9,9 & 116 & 25,2 & 65 & 16,1 & 247 & 18,3 \\
\hline Sibipiruna & Caesalpinia peltophoroides & $\mathrm{N}$ & 5 & 4,1 & 36 & 14,4 & 11 & 9,9 & 58 & 12,6 & 39 & 9,7 & 149 & 11,1 \\
\hline Cinamomo & Melia azedarach L. & $\mathrm{E}$ & 13 & 10,7 & 26 & 10,4 & 16 & 14,4 & 31 & 6,5 & 48 & 11,8 & 134 & 9,9 \\
\hline Ligustro & Ligustro lucidum W. T. Aiton & $\mathrm{E}$ & 31 & 25,4 & 3 & 1,2 & 4 & 3,6 & 46 & 10,0 & 12 & 3,0 & 96 & 7,1 \\
\hline Ingá-feijão & Inga marginata Willd. & $\mathrm{N}$ & 1 & 0,8 & 27 & 10,8 & 12 & 10,8 & 13 & 2,8 & 30 & 7,4 & 83 & 6,2 \\
\hline Ipê-amarelo & Handroanthus chrysotrichus (Mart. ex DC) Mattos & $\mathrm{E}$ & 5 & 4,1 & 16 & 6,4 & 7 & 6,3 & 15 & 3,3 & 18 & 4,5 & 61 & 4,5 \\
\hline Pitangueira & Eugenia uniflora $\mathrm{L}$. & $\mathrm{N}$ & 4 & 3,3 & 4 & 1,6 & 4 & 3,6 & 28 & 6,1 & 14 & 3,5 & 54 & 4,0 \\
\hline Tipuana & Tipuana tipu (Benth.) Kuntze & $\mathrm{E}$ & 7 & 5,7 & 11 & 4,4 & 3 & 2,7 & 10 & 2,2 & 17 & 4,2 & 48 & 3,6 \\
\hline Goiabeira & Psidium guajava $\mathrm{L}$. & $\mathrm{E}$ & 1 & 0,8 & 8 & 3,2 & 7 & 6,3 & 10 & 2,2 & 11 & 2,7 & 37 & 2,7 \\
\hline Jambolão & Syzygium cumini & E & 6 & 4,9 & 5 & 2,0 & 4 & 3,6 & 6 & 1,3 & 15 & 3,7 & 36 & 2,7 \\
\hline Uva-do-Japão & Hovenia dulcis Thumb. & E & 5 & 4,1 & 3 & 1,2 & 1 & 0,9 & 12 & 2,6 & 15 & 3,7 & 36 & 2,7 \\
\hline Ameixeira & Eriobotrya japônica (Thunb.) Lindl. & E & 1 & 0,8 & 11 & 4,4 & 1 & 0,9 & 10 & 2,2 & 7 & 1,7 & 30 & 2,2 \\
\hline Ipê-roxo & Handroanthus heptaphyllus (Vell.) Mattos & $\mathrm{E}$ & 2 & 1,6 & 9 & 3,6 & 1 & 0,9 & 7 & 1,5 & 9 & 2,2 & 28 & 2,1 \\
\hline Amoreira & Morus nigra L. & $E$ & 4 & 3,3 & 4 & 1,6 & 6 & 5,4 & 6 & 1,3 & 4 & 1,0 & 24 & 1,8 \\
\hline
\end{tabular}




\section{REGEIAUFSM}

Rev. Elet. em Gestão, Educação e Tecnologia Ambiental (e-ISSN: 2236-1170)

\begin{tabular}{|c|c|c|c|c|c|c|c|c|c|c|c|c|c|c|}
\hline Chuva-de-ouro & Senna multijuga (Rich) Irwin \& Barneby & $\mathrm{N}$ & & & 13 & 5,2 & 10 & 9,0 & 1 & 0,2 & & & 24 & 1,8 \\
\hline Canafístula & Peltophorum dubium (Spreng.) Taub. & $\mathrm{N}$ & 1 & 0,8 & & & & & 1 & 0,2 & 14 & 3,5 & 16 & 1,2 \\
\hline Grevilea-robusta & Grevillea robusta A. Cunn ex. R. Br. & $\mathrm{E}$ & 1 & 0,8 & 3 & 1,2 & 2 & 1,8 & 9 & 2,0 & 1 & 0,2 & 16 & 1,2 \\
\hline Figueira-comum & Phytolacca dioica $\mathrm{L}$. & $\mathrm{N}$ & & & & & & & & & 14 & 3,5 & 14 & 1,0 \\
\hline Jacarandá-mimoso & Jacaranda mimosifolia & $\mathrm{N}$ & 1 & 0,8 & 9 & 3,6 & & & 3 & 0,7 & 1 & 0,2 & 14 & 1,0 \\
\hline Limoeiro & Citrus limon & $\mathrm{E}$ & & & & & & & 9 & 2,0 & 5 & 1,2 & 14 & 1,0 \\
\hline Araçá-vermelho & Psidium cattleianum & $\mathrm{N}$ & 2 & 1,6 & 3 & 1,2 & 3 & 2,7 & 5 & 1,1 & & & 13 & 1,0 \\
\hline Salso-chorão & Salyx babilônica & $\mathrm{E}$ & & & 1 & 0,4 & & & 6 & 1,3 & 6 & 1,5 & 13 & 1,0 \\
\hline Manduirana & Senna macranthera H.S. Irwin \& Barneby & $\mathrm{N}$ & 2 & 1,6 & 2 & 0,8 & & & 6 & 1,3 & 1 & 0,2 & 11 & 0,8 \\
\hline Palmeira & Areca sp. & $\mathrm{N}$ & & & & & & & & & 10 & 2,5 & 10 & 0,7 \\
\hline Aroeira-vermelha & Schinus terebinthifolius Raddi & $\mathrm{N}$ & & & 1 & 0,4 & & & 3 & 0,7 & 5 & 1,2 & 9 & 0,7 \\
\hline Cedro & Cedrela fissilis Vell. & $\mathrm{N}$ & 4 & 3,3 & 1 & 0,4 & & & & & 4 & 1,0 & 9 & 0,7 \\
\hline Guabirova & Campomanesia xanthocarpa O. Berg & $\mathrm{N}$ & & & 5 & 2,0 & 3 & 2,7 & 1 & 0,2 & & & 9 & 0,7 \\
\hline Guapuruvu & Schizolobium parahyba & $\mathrm{E}$ & & & & & & & 9 & 2,0 & & & 9 & 0,7 \\
\hline Canela-verdadeira & Cinamomum zeylanicum & $\mathrm{E}$ & & & 2 & 0,8 & & & 1 & 0,2 & 4 & 1,0 & 7 & 0,5 \\
\hline Cerejeira & Eugenia involucrata DC & $\mathrm{N}$ & & & 4 & 1,6 & 1 & 0,9 & & & 2 & 0,5 & 7 & 0,5 \\
\hline Laranjeira & Citrus $x$ sinensis & $E$ & & & & & & & 1 & 0,2 & 6 & 1,5 & 7 & 0,5 \\
\hline
\end{tabular}




\section{REGEIAUFSM}

Rev. Elet. em Gestão, Educação e Tecnologia Ambiental (e-ISSN: 2236-1170)

\begin{tabular}{|c|c|c|c|c|c|c|c|c|c|c|c|c|c|c|}
\hline Pata-de-vaca & Bauhinia forficata Link & $\mathrm{N}$ & & & 4 & 1,6 & 2 & 1,8 & 1 & 0,2 & & & 7 & 0,5 \\
\hline Guabiju & Myrcianthes pungens (O. Berg) D. Legrand & $\mathrm{N}$ & 2 & 1,6 & 3 & 1,2 & & & 1 & 0,2 & & & 6 & 0,4 \\
\hline Mangueira & Mangifera indica $\mathrm{L}$. & $\mathrm{E}$ & & & & & & & 2 & 0,4 & 4 & 1,0 & 6 & 0,4 \\
\hline Ariticum & Rolinia salicifolia Schlecht & $\mathrm{N}$ & & & & & & & 1 & 0,2 & 4 & 1,0 & 5 & 0,4 \\
\hline Ficus-benjamina & Ficus benjamina. & E & & & & & & & 4 & 0,9 & 1 & 0,2 & 5 & 0,4 \\
\hline Nogueira & Carya illinoinensis (Wangenh.) K. Koch & $\mathrm{E}$ & & & 1 & 0,4 & & & 2 & 0,4 & 2 & 0,5 & 5 & 0,4 \\
\hline Acer & Acer palmatum Thunb. & $\mathrm{E}$ & & & & & & & & & 4 & 1,0 & 4 & 0,3 \\
\hline Corticeira-do-banhado & Erythrina crista-galli L. & $\mathrm{N}$ & & & & & & & 4 & 0,9 & & & 4 & 0,3 \\
\hline Flamboyant & Delonix regia (Bojer ex Hook.) Raf. & $\mathrm{E}$ & & & & & & & 3 & 0,7 & 1 & 0,2 & 4 & 0,3 \\
\hline Timbaúva & Enterolobium contortisiliquum (Vell.) Morong & $\mathrm{N}$ & 1 & 0,8 & & & 1 & 0,9 & & & 2 & 0,5 & 4 & 0,3 \\
\hline Espirradeira & Nerium oleander L. & $\mathrm{E}$ & & & & & & & 1 & 0,2 & 2 & 0,5 & 3 & 0,2 \\
\hline Jasmim-manga & Plumeria rubra L. & $\mathrm{E}$ & & & & & & & 3 & 0,7 & & & 3 & 0,2 \\
\hline Jerivá & Syagrus romanzoffiana (Cham.) Glassman & $\mathrm{N}$ & & & & & & & & & 3 & 0,7 & 3 & 0,2 \\
\hline Abacateiro & Persea americana Mill. & $\mathrm{E}$ & & & 2 & 0,8 & & & & & & & 2 & 0,1 \\
\hline Acácia-imperial & Cassia fistula $\mathrm{L}$. & E & & & & & & & 2 & 0,4 & & & 2 & 0,1 \\
\hline Bergamoteira & Citrus bergamia & E & & & & & & & 1 & 0,2 & 1 & 0,2 & 2 & 0,1 \\
\hline Ingá-banana & Inga vera Willd. & $\mathrm{N}$ & & & & & & & 1 & 0,2 & 1 & 0,2 & 2 & 0,1 \\
\hline
\end{tabular}




\section{REGEIAUFSM}

Rev. Elet. em Gestão, Educação e Tecnologia Ambiental (e-ISSN: 2236-1170)

\begin{tabular}{|c|c|c|c|c|c|c|c|c|c|c|c|c|c|c|}
\hline Ipê-ouro & Handroanthus Alba (Cham.) Mattos & N & & & & & & & 2 & 0,4 & & & 2 & 0,1 \\
\hline Nespereira & Eryobotria japônica & $\mathrm{E}$ & & & & & & & 2 & 0,4 & & & 2 & 0,1 \\
\hline Platanos & Platanus $x$ acerifolia & $\mathrm{E}$ & & & & & & & & & 2 & 0,5 & 2 & 0,1 \\
\hline Acácia-mimosa & Acacia podalyraefolia A. Cunn. ex G. Don & $\mathrm{E}$ & & & & & & & 1 & 0,2 & & & 1 & 0,1 \\
\hline Açoita-cavalo & Luehea divaricata Mart. & N & & & & & & & 1 & 0,2 & & & 1 & 0,1 \\
\hline Chá-de-bugre & Casearia sylvestris Sw. & N & & & & & & & 1 & 0,2 & & & 1 & 0,1 \\
\hline Eucalipto & Eucalyptus sp. & $\mathrm{E}$ & & & & & & & 1 & 0,2 & & & 1 & 0,1 \\
\hline Falsa-canela & Cinnamomum zeylanicum Blume & $\mathrm{N}$ & & & & & & & 1 & 0,2 & & & 1 & 0,1 \\
\hline Grevilha-anã & Grevillea banksii R. Br. & $\mathrm{E}$ & & & & & & & 1 & 0,2 & & & 1 & 0,1 \\
\hline Guajuvira & Cordia americana L. & $\mathrm{N}$ & & & 1 & 0,4 & & & & & & & 1 & 0,1 \\
\hline Magnólia & Magnolia grandiflora L. & $\mathrm{E}$ & & & & & & & 1 & 0,2 & & & 1 & 0,1 \\
\hline Pau-ferro & Caesalpinia ferrea Benth. & $\mathrm{E}$ & & & & & 1 & 0,9 & & & & & 1 & 0,1 \\
\hline Pessegueiro-do-mato & Eugenia mircianthes Nied. & $\mathrm{N}$ & & & & & & & 1 & 0,2 & & & 1 & 0,1 \\
\hline & Total & & 122 & 100 & 250 & 100 & 111 & 100 & 461 & 100 & 404 & 100 & 1348 & 100 \\
\hline
\end{tabular}

Onde: $\mathrm{O}=$ Origem; $\mathrm{E}=$ Exótica, $\mathrm{N}=$ Nativa; $\mathrm{NI}$ = Número de indivíduos. 
Rev. Elet. em Gestão, Educação e Tecnologia Ambiental (e-ISSN: 2236-1170)

Americana/SP - 58,6\% das espécies (Silva, 2005), e Mariápolis/PR - 63,2\% das espécies (Silva et al., 2008).

Klein (1985) afirma que o sucesso obtido, por meio da introdução das espécies exóticas, se deve a fatores como a adequada seleção das espécies, metodologia silvicultural desenvolvida e grande facilidade de coleta de sementes, porém, sendo as nativas o resultado de seleção durante muitos séculos, elas representam as mais adequadas para manter a dinâmica do solo e clima regional. Redin et al. (2010) e Prass (2004) observaram que as espécies de maior ocorrência são exóticas, destacando a elevada frequência de jacarandá nas praças de Cachoeira do Sul e extremosa na cidade de Quinze de Novembro, respectivamente.

A alta frequência de espécies exóticas, demonstrada no presente estudo revela ausência de preocupação com a conservação da flora nativa. Santos e Teixeira (2001) e Lorenzi et al. (2003) afirmam que em praticamente todas as cidades brasileiras há uma predominância na utilização de espécies exóticas na arborização urbana, deixando-se de explorar a riqueza da flora local. Para Miller, 1997, isto se deve a maior facilidade de adaptação destas espécies a ambientes hostis e alterados. O uso de espécies nativas da região para compor a arborização, trazem inúmeras vantagens, como: maior resistência a pragas, a criação de um banco genético ex-situ, a minimização do risco de uso de espécies exóticas invasoras, etc (Biondi e Leal, 2008). Outros benefícios são reportados por Brun et al. (2007), onde afirmam que espécies animais nativas dos arredores urbanos podem beneficiar-se com as fontes de abrigo e alimento (flores e frutos) geradas pelas árvores urbanas. A oferta desses recursos ocorre ao longo de todo ano propiciando fortes níveis de interação com a fauna regional (Reis et al., 2003). Pensando em escala maior, essas árvores nativas, conectadas a praças e parques, podem funcionar como corredores ecológicos. Pennignton et al. (2008), ao analisarem as preferências de habitats de aves migratórias em áreas urbanas, relataram que aves neotropicais migratórias em trânsito preferiram usar árvores nativas e mais maduras, muito possivelmente devido à maior oferta de recursos alimentares.

A análise dos parâmetros morfométricos das sete espécies mais representativas da arborização das vilas em questão mostra que o ingá-feijão possui o maior porte, seguido do ipêamarelo e cinamomo (Tabela 3). A altura total média dos indivíduos mais frequentes na arborização das áreas estudadas foi de 4,8 m, altura da primeira bifurcação 1,0 m, DAP médio de $12 \mathrm{~cm}$, altura de inserção da copa de 2,3 m e altura de inserção do primeiro galho de 1,1 m. No inventário realizado por Rossetti et al. (2010) em dois bairros paulistanos, a altura média de todas as árvores foi de 8,07 $\mathrm{m}$ e a altura da bifurcação, 1,97 m. Em levantamento da arborização em Estância das Águas de São Pedro, Bortoleto (2004) observou, altura média de 5,10 m e DAP de 38 $\mathrm{cm}$. Comparando-se o resultado do presente estudo com os autores anteriormente citados, conclui-se que as principais espécies da arborização de cinco vilas do bairro Camobi são de plantios recentes na sua maioria. Além do mais, a remoção de indivíduos arbóreos de grande porte no momento da construção de casas, prédios, asfaltamento, etc., faz com que haja plantios de árvores em substituição, e assim a arborização urbana se torna mais jovem.

Os parâmetros morfométricos da extremosa apresentaram uma média de 3,6 metros de altura total, 1,9 metros de altura de copa, o DAP médio para a espécie foi de $7,8 \mathrm{~cm}$ nas áreas avaliadas, já no estudo de Bortoleto et al. (2007), o DAP médio para espécie na arborização de vias públicas na Estância de Águas de São Pedro, SP variou de 11,0 a $15 \mathrm{~cm}$, o que demonstra que o desenvolvimento dos indivíduos encontra-se abaixo do normal para espécie, assim como a altura total, onde se encontra como ideal para espécie em torno de 7,0 m (Backes e Irgang, 2004). Em relação à altura, os indivíduos desta espécie podem tem sofrido podas muito severas e/ou 
REGEJAFSM SZYMCZAK et al., v(8), no 8, p. 1611-1625, SET-DEZ, 2012.

Rev. Elet. em Gestão, Educação e Tecnologia Ambiental (e-ISSN: 2236-1170)

realizadas de forma inadequada. Muitas vezes a própria população faz essa intervenção, por ser uma árvore de fácil manuseio.

Para os parâmetros da copa observou-se uma altura de 0,9 metros para o primeiro galho e 0,9 metros de altura da primeira bifurcação. As baixas alturas de primeiro galho e bifurcação se devem principalmente ao emprego de mudas com altura inadequada para arborização de vias públicas, com altura inferior ao recomendado $(<1,60 \mathrm{~m})$ e poda realizada muito prematuramente, o que dão aspecto arbustivo aos indivíduos e maior necessidade de poda, para conformar o indivíduo ao espaço de desenvolvimento e circulação dos pedestres. Colocar um autor que fale da altura mínima $(1,80 \mathrm{~m})$

O ligustro apresentou uma média de 4,7 metros de altura total, 2,1 metros de altura de copa, o valor encontra-se adequado (Gonçalves e Paiva, 2006), para que se permita a livre circulação dos transeuntes no calçamento, e 1,0 metros de primeiro galho e 0,6 metros de altura da bifurcação, e DAP médio de 13,9 cm.

Tabela 3 - Parâmetros morfométricos das espécies de maior frequência na arborização urbana da área do estudo, Bairro Camobi, Santa Maria, RS, 2008.

Table 3 - Morphometrics standards of species the most frequency in forestry urban in study area, 2008.

\begin{tabular}{ccccccc}
\hline Nome Comum & Nome Científico & $\mathbf{H t}(\mathbf{m})$ & $\mathbf{H c}(\mathbf{m})$ & $\mathbf{H g}(\mathbf{m})$ & $\mathbf{H b}(\mathbf{m})$ & $\mathbf{D A P}(\mathbf{c m})$ \\
\hline Cinamomo & Melia azedarach L. & 5,6 & 2,7 & 1,1 & 1,3 & 19,4 \\
Extremosa & Lagerstroemia indica L. & 3,6 & 1,9 & 0,9 & 0,9 & 7,8 \\
Ingá-feijão & Inga marginata Willd. & 6,4 & 2,4 & 1,0 & 1,2 & 13,0 \\
Ipê-amarelo & Handroanthus chrysotrichus (Mart. ex DC) Mattos & 5,9 & 2,8 & 1,7 & 1,5 & 13,4 \\
Ligustro & Ligustro lucidum W. T. Aiton & 4,7 & 2,1 & 1,0 & 0,6 & 13,9 \\
Pitangueira & Eugenia uniflora L. & 3,1 & 1,7 & 0,7 & 0,8 & 5,7 \\
Sibipiruna & Caesalpinia peltophoroides & 5,4 & 2,8 & 1,1 & 1,0 & 12,6 \\
\hline Média Geral & & $\mathbf{4 , 8}$ & $\mathbf{2 , 3}$ & $\mathbf{1 , 1}$ & $\mathbf{1 , 0}$ & $\mathbf{1 2 , 0}$ \\
\hline
\end{tabular}

O cinamomo possui um DAP médio elevado comparado às demais espécies evidenciando que sua presença na arborização é de longa data. Considerando o diâmetro do cinamomo nota-se que a espécie está a bastante no local. A mesma pode vir a apresentar problemas fitossanitários ou de queda com vendavais. A frequência dele em relação ao total de indivíduos do inventário é de $9,9 \%$ concordando com a literatura onde o valor recomendado é que não se ultrapasse $10 \%$ do número total de indivíduos (Silva Filho e Bortoleto, 2005). Dessa maneira evitam-se problemas com disseminação de doenças fitopatológicas.

Entre as espécies nativas do Brasil, ingá-feijão e sibipiruna possuem valores de parâmetros morfométricos similares, sendo mais frequente na vila Santos Dumont e na vila Santa Tereza, respectivamente. São espécies as quais a população tem preferência por serem perenes e produzem sombra abundante.

Em relação a conflitos com a rede elétrica, aproximadamente $85 \%$ das árvores apresentaram altura inferior a $6 \mathrm{~m}$, às quais, teoricamente, sofreriam apenas conflitos com os 
REGETHFSM SZYMCZAK et al., v(8), no 8, p. 1611-1625, SET-DEZ, 2012.

Rev. Elet. em Gestão, Educação e Tecnologia Ambiental (e-ISSN: 2236-1170)

cabos aéreos de telefone. Acima de $6 \mathrm{~m}$ e inferior a $11 \mathrm{~m}$ de altura encontrava-se apenas indivíduos de ipê-amarelo conflitando com a rede de baixa tensão. De acordo com CEMIG (2011) das espécies avaliadas apenas a extremosa é adequada para plantios debaixo de redes elétricas. As demais, sem poda frequente, podem causar problemas em um futuro muito próximo. Aproximadamente $57 \%$ dos indivíduos com altura inferior a $6,0 \mathrm{~m}$ apresentaram DAP superior a 10 $\mathrm{cm}$, indicando plantas na fase adulta que sofreram intervenções de poda, caracterizando a redução do seu porte.

\section{CONCLUSÕES}

Há um predomínio de espécies exóticas na arborização, deixando-se de valorizar a flora nativa local que possui espécies de grande valor paisagístico pertencentes ao bioma Mata Atlântica, como: camboatá, guajuvira, canela.

O uso indiscriminado de indivíduos de extremosa poderá apresentar problemas de ataque de pragas e doenças que além de torna-los esteticamente degradados poderá representar riscos de contaminação para as demais espécies adjacentes. O ligustro, com suas propriedades alergênicas, representa uma preocupação à saúde dos moradores.

A redução no número de indivíduos das principais espécies componentes da arborização urbana do bairro Camobi, devido ao aumento de áreas construídas, é fato preocupante que deve ser fiscalizado pelos órgãos responsáveis. Muitas vezes a supressão é realizada clandestinamente para facilitar o processo de urbanização.

A arborização pode ser considerada recente (jovem) e precisa de tratos silviculturais adequados e de zelo da população para que cumpra seu papel de oferecer qualidade de vida aos moradores deste bairro.

\section{AGRADECIMENTOS}

A Fundação de Amparo à Pesquisa do Estado do Rio Grande do Sul (FAPERGS) pela concessão de auxílio para realização da pesquisa e ao CNPq pela bolsa de iniciação científica à primeira autora.

\section{REFERÊNCIAS BIBLIOGRÁFICAS}

ANDRADE, T. O. Inventário e análise da arborização viária da Estância Turística de Campos de Jordão, SP. 2002. 112 f. Dissertação (Mestrado em Agronomia) - Escola Superior de Agricultura Luiz de Queiroz, Piracicaba.

BACKES, P.; IRGANG, B. Mata Atlântica: as árvores e a paisagem. Porto Alegre: Paisagem do Sul, 2004. $396 \mathrm{p}$. BIONDI, D.; LEAL, L. Caracterização das plantas produzidas no Horto Municipal da Barreirinha - Curitiba / PR. Rev. SBAU, Piracicaba, v.3, n.2, p. 20-36, jun. 2008.

BORTOLETO, S. Inventário qualiquantitativo da arborização viária da Estância de Águas de São Pedro - SP. 2004. 85 f. Dissertação (Mestrado em Agronomia) - Escola Superior de Agricultura Luiz de Queiroz, Piracicaba. 
Rev. Elet. em Gestão, Educação e Tecnologia Ambiental (e-ISSN: 2236-1170)

BORTOLETO, S.; SILVA FILHO, D. F.; SOUZA, V. C.; FERREIRA, M. A. P.; POLIZEL, J. L.; RIBEIRO, R. C. S. Composição e distribuição da arborização viária da estância de águas de São Pedro-SP. REVSBAU, Piracicaba - SP, v.2, n.3, p.32-46, 2007.

BRUN, F.G.K. ; LONGHI, S.J. ; BRUN, E.J. Espécies com Princípios Tóxicos, empregadas na Arborização Urbana do Bairro Camobi - Santa Maria, RS. In: IV SIMPÓSIO DE PÓS-GRADUAÇÃO EM CIÊNCIAS FLORESTAIS. Piracicaba, SP. 2006.

BRUN, F.G.K. ; LONGHI, S.J. ; BRUN, E.J. Estudo da percepção da população de vilas do Bairro Camobi, Santa Maria - RS sobre a arborização urbana. Revista de Estudos Ambientais, v. 11, n. 1, p. 6-21, jan./jul., 2009. BRUN, F.G.K.; LINK, D.; BRUN, E.J. O emprego da arborização na manutenção da biodiversidade de fauna em áreas urbanas. Rev. SBAU, Piracicaba, v.2, n.1, p. 117-127, 2007.

CARVALHO, S; MIRANDA,T. Levantamento quantitativo e qualitativo de indivíduos arbóreos presentes nas vias do bairro da ronda em Ponta Grossa-PR. REVSBAU, Piracicaba - SP, v.4, n.3, p.143 - 157, 2009. CEMIG - Companhia Energética de Minas Gerais. Manual de arborização. Belo Horizonte: Cemig / Fundação Biodiversitas, 2011.

FARIA, J. L. G; MONTEIRO, E.A; FISCH, S. T. V. Arborização de Vias públicas no município de Jacareí - SP. REVSBAU, Piracicaba, v.2, n.4, p.20-33, 2007.

FONTOURA, R. H. R. Diagnóstico e prognóstico da Vila Tonetto - Camobi. 1993. 50 f. Monografia (Bacharelado em Geografia), Curso de Geografia- Universidade Federal de Santa Maria, Santa Maria. GERHARDT, M. C; MULLER, M. G; WOLSKI, S. R. S. Diagnóstico da arborização da área central da cidade de Santo Cristo - RS. REVSBAU, Piracicaba - SP, v. 6, n. 1, p. 69-84, 2011.

GONÇALVES, W; PAIVA, H. N. Árvores para o ambiente urbano. Viçosa: Aprenda Fácil, 2004. 242 p.(Coleção Jardinagem e Paisagismo, 3).

GONÇALVES, W; PAIVA, H. N. Silvicultura Urbana: implantação e manejo. Viçosa: Aprenda Fácil, 2006. 201 p. (Coleção Jardinagem e Paisagismo, 4).

GREY, G.M. \& DENEKE, F.J. Urban Forestry. New York: John Wizey, 1978. 279p.

GUZZO, P. Alterações ambientais em áreas urbanas, planejamento e legislação ambiental. In: SEMINÁRIO LATINO AMERICANO DE PLANEJAMENTO URBANO, 1. Campo Grande, MS. 1993.

IBGE - INSTITUTO BRASILEIRO DE GEOGRAFIA E ESTATÍSTICA. Disponível em: <http://www.ibge.gov.br>. Acesso em 20 de Janeiro de 2000.

KLEIN, R.M. Síntese ecológica da floresta estacional da Bacia do Jacuí: importância do reflorestamento com essências nativas (RS). In: CONGRESSO FLORESTAL ESTADUAL, 1985, Nova Prata, RS. Anais... Nova Prata: PMNP, 1985. p. 265-278.

LANGOWSKI, E.; KLECHOWICZ, N. A. Manual Prático de Poda e Arborização Urbana. Cianorte: APROMAC, 2001.

LONGHI, S.J; MONTEIRO, J.S; BRUN, F.G.K. Aspectos da arborização do bairro Camobi, Santa Maria - RS. 2005. 45 p. Relatório final de pesquisa.

LORENZI, H., SOUZA, H. M. TORRES, M. A.V BACHER, L. B. Árvores exóticas no Brasil: madeireiras, ornamentais e aromáticas. São Paulo: Nova Odessa, 2003,368 p.

MENEGHETTI, G. I. P. Estudo de dois métodos de amostragem para inventário da arborização de ruas dos bairros da orla marítima do município de Santos - SP. 2003. 100 f. Dissertação (Mestrado em Recursos Florestais) - Escola Superior de Agricultura Luiz de Queiroz, Piracicaba.

MILANO, M. S. Avaliação e análise da arborização de ruas de Curitiba - PR. 1984. 130 f. Dissertação (Mestrado em Ciências Florestais) - Universidade Federal do Paraná, Curitiba.

MILLER, R.W. Urban Forestry: planning and managing urban greenspaces. 2 nd ed. New Jersey: PrenticeHall, 1997.

MORENO, J. A. Clima do Rio Grande do Sul. Porto Alegre: Secretaria da Agricultura, 1961. 73 p.

PAINE, T. D.; MILLAR, J. G.; BELLOWS, T. S.; HANKS, L. M.; GOULD, J. R. Integrating classical biological control with plant hearth in the urban forest. Journal of Arboriculture, Urban, v. 19, n. 3, p. 125-130, 1993.

PRASS, C. H. Avaliação da arborização urbana na cidade de Quinze de Novembro - RS. Santa Maria. 2004. p. 64. (Relatório de Estágio Curricular) - Universidade Federal de Santa Maria, Santa Maria.

PREFEITURA MUNICIPAL DE SANTA MARIA. Mapa da cidade de Santa Maria, 22a edição, 2002. 
Rev. Elet. em Gestão, Educação e Tecnologia Ambiental (e-ISSN: 2236-1170)

REDIN, C, G; VOGEL, C; TROJAHN, C,D.P; GRACIOLI, C.R. LONGHI, S, J. Análise da arborização urbana em cinco praças do município de Cachoeira do Sul, RS. REVSBAU, Piracicaba - SP, v.5, n.3, p.148-164, 2010. REIS, A.; ANJOS, A. dos; BECHARA, F.C. Critérios para a seleção de espécies na arborização urbana ecológica. Sellowia, n. 53-55, p. 51-67, maio 2003.

ROCHA, R. T.; TELES, P. S. S.; NETO, S. N. O. Arborização de vias públicas em Nova Iguaçu, RJ: O caso dos Bairros Rancho Novo e Centro. Revista Árvore, Viçosa, v. 28, n. 4, p. 599-607, 2004.

RODRIGUES, M. G. R; BREDT, A; UIEDA, W. Arborização de Brasília, Distrito Federal, e possíveis fontes de alimentos para morcegos fitófagos. In: CONGRESSO BRASILEIRO DE ARBORIZAÇÃO URBANA, 2.; ENCONTRO NACIONAL SOBRE ARBORIZAÇÃO URBANA, 5., 1994, São Luis, MA. Anais... São Luis, MA: Sociedade Brasileira de Arborização Urbana, 1994. p. 311 - 318.

ROSSETTI, A. I. N; TAVARES, A. R; PELLEGRINO, P. R. M. Inventário arbóreo em bairros Paulistanos, Jardim da Saúde e Vila Vera, localizados na subprefeitura de Ipiranga. Revista Árvore, Viçosa-MG, v. 34, n. 5, p. $889-898,2010$.

SANTA MARIA DADOS. Dados e estatísticas de Santa Maria. Disponível em: < http://www.santamariadados.com.br>. Acesso em 23 de maio de 2005.

SANTOS, N. R. Z.; TEIXEIRA, I. F. Arborização de vias públicas: ambiente $\mathbf{x}$ vegetação. Instituto Souza Cruz. Porto Alegre: Pallotti, 2001. 136p.

SILVA FILHO, D. F. Cadastramento informatizado, sistematização e análise da arborização das vias públicas da área urbana do município de Jaboticabal, SP. 2002. Dissertação (Mestrado em Geografia), Universidade Estadual Paulista, Jaboticabal.

SILVA FILHO, D. F; BORTOLETO, S. Uso de indicadores de diversidade na definição de plano de manejo da arborização viária de Águas de São Pedro - SP. Revista Árvore, v. 29, n. 6, p. 973-982, 2005.

SILVA, L. F. Situação da arborização viária e proposta de espécies para os bairros Antônio Zanaga l e II, da cidade de Americana/SP. 2005. 80 f. Dissertação (Mestrado em Agronomia) - Escola Superior de Agricultura Luiz de Queiroz, Piracicaba.

SILVA, L. M, et al. Inventário da arborização em duas vias de Mariápolis/PR. REVSBAU, v. 3, n. 1, p. 36 - 53, 2008.

SOUZA, H. M. Algumas espécies nativas para arborização de vias públicas. In: CONGRESSO BRASILEIRO DE ARBORIZAÇÃO URBANA, 2, ENCONTRO NACIONAL SOBRE ARBORIZAÇÃO URBANA, 5, São Luis, MA. Anais... São Luis: Sociedade Brasileira de Arborização Urbana, 1994. p.67-74.

SPIAZZI, C. F. T. Análise dos aspectos populacionais, infra-estrutura e equipamentos urbanos das Vilas Soares do Canto, Jardim e Aparício de Moraes no Bairro Camobi - Santa Maria - RS. 2002. 67 f. Monografia (Bacharelado em Geografia), Curso de Geografia- Universidade Federal de Santa Maria, Santa Maria.

STRECK, E. V.; KÄMPF, N.; DALMOLIN, R. S. D.; KLAMT, E.; NASCIMENTO, P. C.; SCHNEIDER, P.; GIASSON, E.; PINTO, L. F. S. Solos do Rio Grande do Sul. Porto Alegre: UFRGS, 2008. 222 p.

TEIXEIRA, I. F. Análise qualitativa da arborização de ruas do Conjunto habitacional Tancredo Neves, Santa Maria, RS. Ciência Florestal, Santa Maria, v.9, n.2, p.9-21, 1999.

VIERA, V. Uso do solo urbano do Bairro Camobi - Setor Sul: 1966 - 1992, Santa Maria, RS. 1997. $69 \mathrm{f}$. Monografia (Bacharelado em Geografia), Curso de Geografia- Universidade Federal de Santa Maria, Santa Maria. 